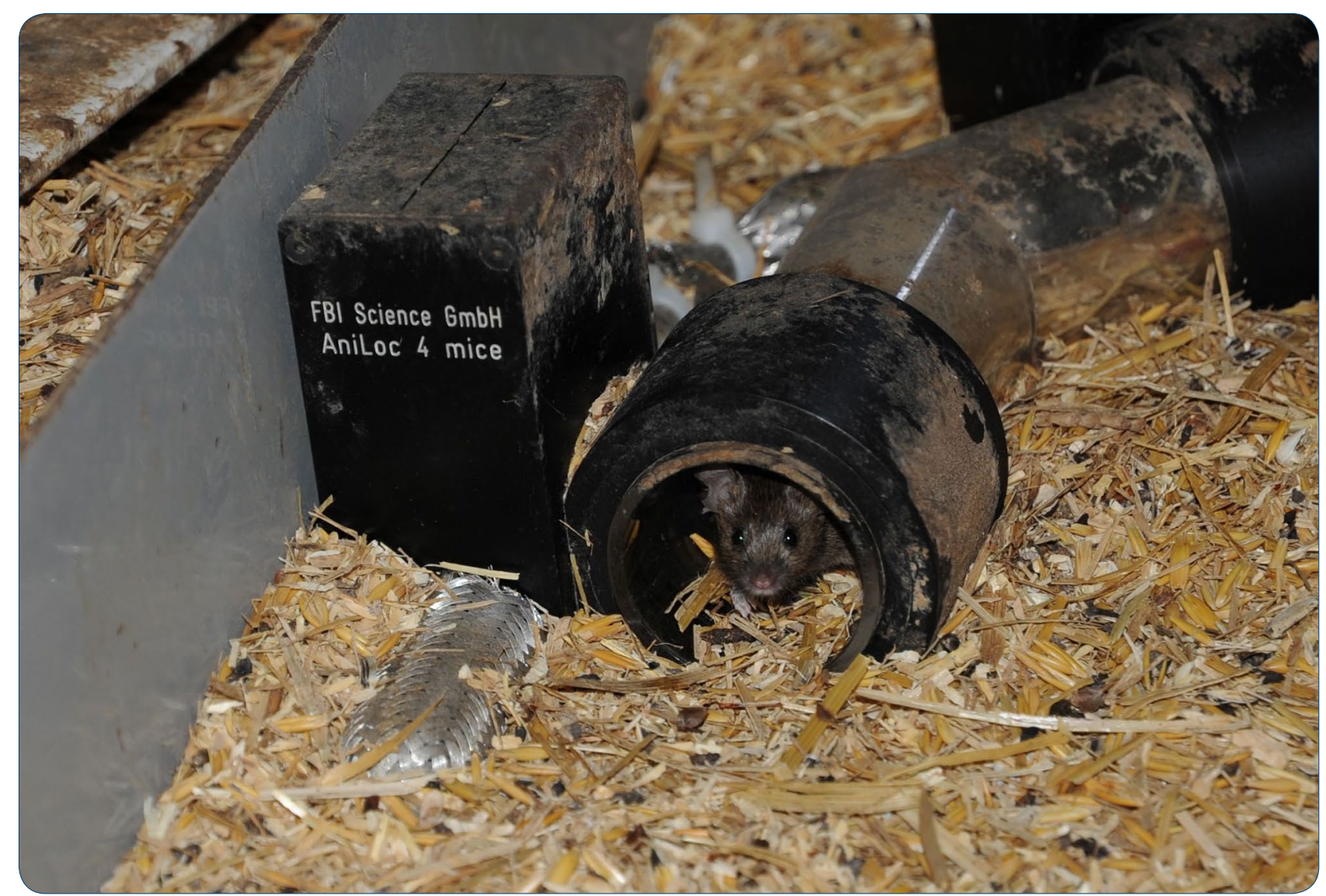

\title{
A system for automatic recording of social behavior in a free-living wild house mouse population
}

König et al. 


\title{
A system for automatic recording of social behavior in a free-living wild house mouse population
}

\author{
Barbara König ${ }^{1 *}$, Anna K. Lindholm¹', Patricia C. Lopes ${ }^{1}$, Akos Dobay ${ }^{1}$, Sally Steinert ${ }^{1}$ \\ and Frank Jens-Uwe Buschmann²
}

\begin{abstract}
Background: Our research focuses on mechanisms that promote and stabilize social behavior, fitness consequences of cooperation, and how interactions with conspecifics structure groups and populations. To this end, we studied wild house mice (Mus musculus domesticus) in the laboratory, in semi-natural enclosures and in the field. In 2002, we initiated a project on a free-living population of house mice in a barn near Zurich, Switzerland, where mice were equipped with RFID transponders and were provided with 40 nest boxes for resting and breeding. The population typically comprised between 250 and 400 mice.

Methods: To analyze social group membership, social interactions and social preferences of the mice in our study population over their lifespan, we installed a continuous transponder reading system (AniLoc, FBI Science GmbH, Germany). Mice accessed nest boxes through tunnels equipped with two antennas each. When a mouse implanted with an RFID transponder passed the electromagnetic field of an antenna, its identity was transmitted and registered in real time with AniLoc. Additionally, body weights of mice were automatically registered at eight drinking facilities (Intelliscale, FBI Science GmbH, Germany). Here, a mouse sits on a freely movable platform that connects to a scale registering body weight when drinking, and an antenna around the head of the water bottle registers the drinking individual's RFID transponder.
\end{abstract}

Results: The system enabled continuous remote monitoring of the behavior of a free-living, open population of house mice, when using nest boxes and when drinking. Since such safe places are an important resource for survival and reproduction, time of day, duration and frequency of meetings with conspecifics reveal information about the function of their interactions. Trigger efficiency of antennas was $98.2 \%$. Mice entered and left the nest boxes with an average speed of $0.03 \mathrm{~m} / \mathrm{s}$, which is within the antennas' detection capacity (detection speed of $1 \mathrm{~m} / \mathrm{s}$ or $3.6 \mathrm{~km} / \mathrm{h}$ ). The antenna devices documented not only social structuring of our study population but also spatial genetic structuring. The observation that mice lived in rather closed social groups and tended to share nest boxes with relatives highlights the importance of kin selection for the evolution and maintenance of social behavior.

Conclusions: We suggest that such automatic recording of activity, spatial distribution and social interactions is helpful not only in field studies, for a variety of species, but also in captivity or laboratory studies, to answer basic questions in behavioral ecology, population ecology, population genetics, conservation biology, disease ecology, or animal welfare.

Keywords: AniLoc, Cooperation, Demography, House mice, Population ecology, RFID technology, Relatedness, Social networks

\footnotetext{
*Correspondence: barbara.koenig@ieu.uzh.ch

${ }^{1}$ Institute of Evolutionary Biology and Environmental Studies, University

of Zurich, Winterthurerstrasse 190, 8057 Zurich, Switzerland

Full list of author information is available at the end of the article
} 


\section{Background}

Documenting individual behavior of wild animals over an extended period of time is essential for many studies in behavioral ecology. During the last decades, an increasing number of investigations used RFID tags to individually mark animals in the field with the aim to gain information on a species' population ecology or social behavior. Radio-frequency identification (RFID) refers to a non-contact data transmission technology comprising a transponder (attached to an animal or implanted under its skin) and a receiver (reviewed by [1]). Miniaturized passive-integrated transponder (PIT) tags, which use the energy of the electromagnetic field of the receiver, provide reliable long-term identification not only in wildlife studies, but also in livestock, laboratory animals, zoo animals or pets. In connection with automated monitoring systems, PIT tags further allow innovative investigations of various aspects of animal behavior, with little, if any, effect on the physiology or behavior of the study animals (for a recent review, see [2]). In vertebrates, such an automated approach has been successfully applied in population ecology or behavioral ecology studies with fish [3, 4], amphibians [5], birds (to give a few examples: [6-10]; for a more detailed review, see [11]), and small mammals [12-16].

Since 2002, we have studied a free-living population of house mice (Mus musculus domesticus) in a barn near Zurich, Switzerland. We use PIT tags for individual identification to analyze the species' reproductive and social behavior. Initially, we regularly registered the presence of mice in the nest boxes provided in the barn with handheld readers, and monitored all litters born (for details see the section "The study population", and [17]). A characteristic aspect of female social behavior proved to be communal nursing. Two, or more, females pool their litters in a communal nest and indiscriminately care for and nurse own offspring and the pups of the social partner(s) [18-23]. One-third of all litters in our study population were raised communally [24].

Due to the high energetic costs of lactation, we expected females to preferentially nurse own offspring, which was not observed [20,21,25]. Communal nursing, therefore, is one of the few examples in mammals in which regular nursing of non-offspring occurs, and thus provides a very good example to test basic ideas about social cooperation. Understanding the evolution of cooperative behavior is one of the greatest challenges in evolutionary biology and social sciences [26-28].

So far, social cooperation in house mice has been mostly studied in the laboratory or in semi-natural enclosures. In those studies, non-offspring nursing proved to be an integral part of the reproductive behavior of female house mice (for a recent review on communal nursing in house mice, see [29]). Such laboratory studies standardize the availability of resources necessary for reproduction (food, nesting sites) and the social environment (size and composition of a group). They allow testing predictions on the effect of number of females per group or genetic relatedness among group members on the propensity to cooperate [23]. In their natural environment, however, house mice live in rather flexible social groups; they encounter a variety of conspecifics every day and are exposed to emigration or immigration of mice (for reviews see [17, 30]). Both sexes may mate with several partners during a reproductive event (revealing a polygynandrous mating system; [31-33]), and females contribute to territorial defense and may even cooperate in offspring defense [30,33]. Free-living house mice are not easily observed, since they are small, fast moving, mainly active after dusk until dawn, and hide, rest and reproduce in sheltered places inaccessible to predators (and human observers). Collecting long-term data on house mouse social and reproductive behavior, therefore, requires direct encounter mapping technology that automatically registers the timing of behavioral interactions among individually identifiable mice. Krause and coworkers recently reviewed the most promising approaches of RFID technology in the emerging field of "reality mining" in the context of social behavior [1].

Here, we describe an RFID-based recording system (AniLoc) that we installed in the barn inhabited by our study population of house mice in December 2012. This system is a technically improved version of a previous prototype, installed in 2007 (by the company NewBehavior AG, Zurich, Switzerland). AniLoc is a permanent, continuous transponder reading system that allows direct encounter mapping of social interactions among adult mice in the nest boxes provided.

Besides describing the AniLoc system, we further present illustrations of data analyses that rely on the timing and duration of encounter mapping as used in our study. Detailed analyses over longer time periods are in preparation. In combination with molecular investigations of the genetic relatedness among interacting individuals, such behavioral data will allow examination of the fitness consequences of social interactions and the benefits of communal versus solitary nursing of litters, contributing to the fields of social evolution and social selection.

\section{Methods}

\section{The study population}

Since 2012, we have studied a population of wild house mice in a $72 \mathrm{~m}^{2}$ barn, situated at the border of a forest near Illnau, Kanton Zürich, Switzerland (Fig. 1; for a detailed description see [17]). 


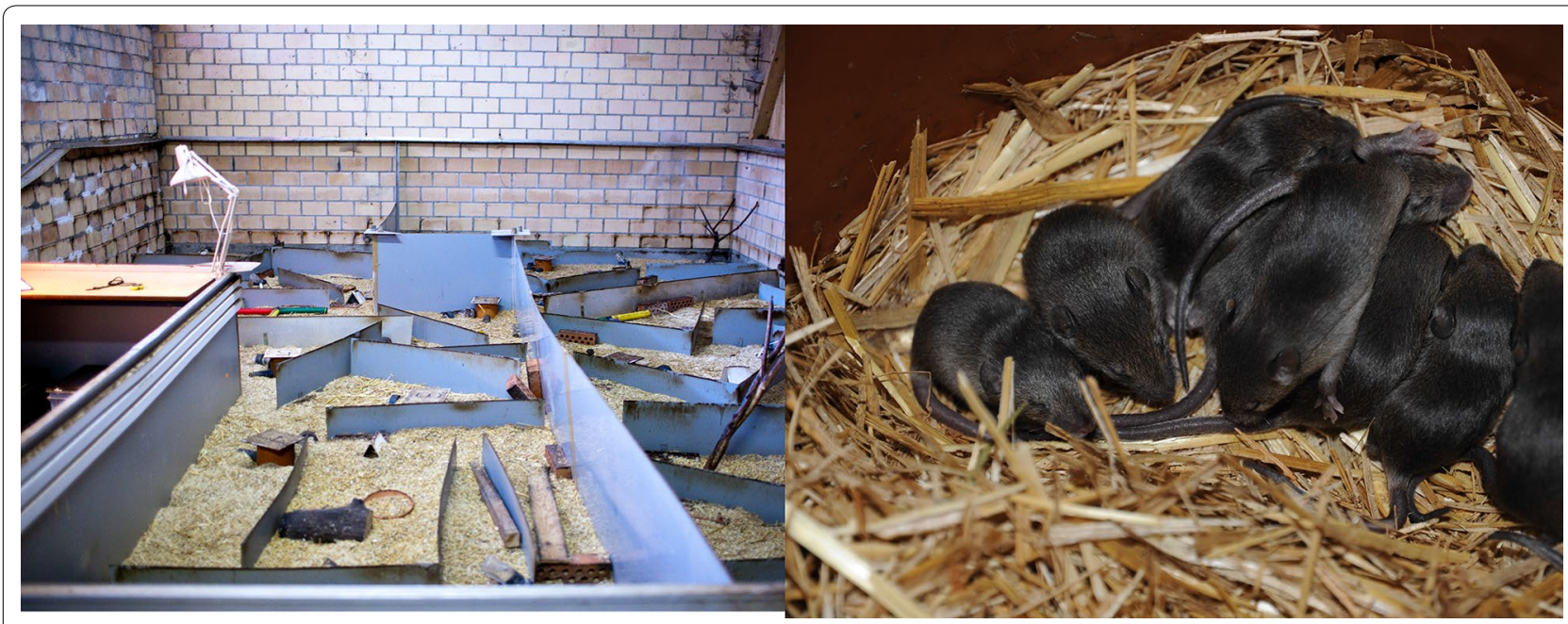

Fig. 1 Our study site in a barn near Zurich, Switzerland. Left the study population of house mice inhabits a $72 \mathrm{~m}^{2}$ former agricultural building (barn) that is open to dispersal but closed to predators. Right nest boxes can be opened to monitor reproduction (age and number of pups in litters)

A barn is a natural habitat for a house mouse. House mice in Europe occur in anthropogenic habitats, commensally with humans, such as grain stores and farm buildings; feral populations are generally restricted to islands $[34,35]$.

The barn with the study population was divided into four quarters by aluminum plates, with holes allowing the passage of mice, and bricks as well as wooden and plastic barriers providing internal structure and shelters (Fig. 2). Mice could access all parts of the barn, and could leave it under the roof or through holes in the walls.

The mice nested in 40 artificial nest boxes (ten per quarter; Fig. 2) and were provided with straw as nesting material. The interiors of the nest boxes were accessible to us, so that offspring could be counted and measured (Fig. 1). Each nest box had openings for two tubes. One was a transparent tunnel through which mice entered and left a box (it is not necessary to use transparent tubes, but we found it helpful that we can see inside). The other tube was shorter and opaque, and was closed with a plug (unplugging those tubes facilitated catching and handling of mice from nest boxes during our regular population monitoring).

Nest boxes and shelters were monitored weekly for the presence of mice (using handheld transponder readers) and for new litters. The ages of pups were estimated, and all litters were measured and sexed shortly before weaning (at 13 days of age, day of birth of a litter was considered day 1). We also took small tissue samples from the ear for later genetic analyses. In addition, at approximately 7-week intervals, comprehensive trapping was conducted to monitor the entire population. Every mouse was weighed, adult males and females were examined for reproductive state, and those adults lacking transponders (see below) were tagged. We also monitored the population for remains of deceased mice. During the last 5 years, the population comprised 250-430 individuals (we observed seasonal variation, with the lowest numbers during winter; [17]).

Water and food, a 50/50 mixture of oats and commercial rodent food made by Haefliger AG, were provided ad libitum at twelve feeding trays (three per quarter). We considered the availability of food within the natural range. The barn itself was free of predators, but not of parasites, and mice were exposed to predators, including foxes, badgers, house cats and birds of prey, whenever they exited the barn.

\section{RFID technology used}

Male and female mice of minimally $18 \mathrm{~g}$ were subcutaneously implanted with PIT tags of unique radio-frequency identification (RFID). In our study, we used RFID tags from Euro ID Identifikationssysteme $\mathrm{GmbH} \& \mathrm{Co}$, Germany (trovan ${ }^{\circledR}$ ID 100, $0.1 \mathrm{~g}$ weight, $11.5 \mathrm{~mm}$ length, $2.1 \mathrm{~mm}$ diameter). The transponders provided a unique 10 digit alpha-numeric code for each mouse, and a means to monitor mice remotely by transponder readers.

\section{Continuous recording of RFID transponders}

In spring 2007, we installed the first automatic transponder reading prototype (NewBehavior AG, Zurich, Switzerland), which we replaced in December 2012 with the current, more efficient AniLoc system (FBI Science $\mathrm{GmbH}$, Germany). The system was designed to track animals entering and leaving nest boxes, or accessing drinking devices. 


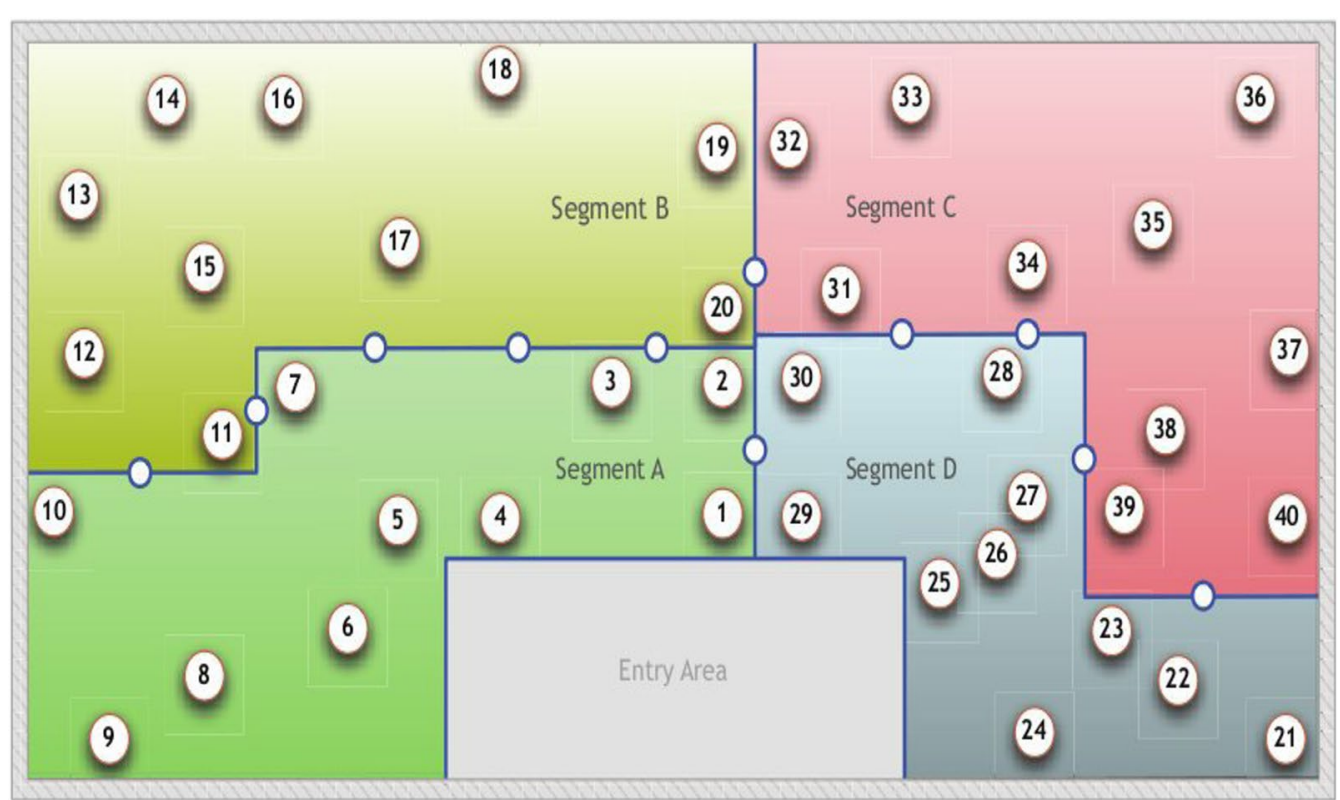

Artificial nestboxes with numbering

Dividers with small transit holes (circles)

Fig. 2 Schematic drawing of the barn. The barn has a floor space of $72 \mathrm{~m}^{2}$, and is equipped with 40 artificial nest boxes. Aluminum dividing walls are $75 \mathrm{~cm}$ high, with 11 passages between the four areas. Next to the entrance door into the barn is a separate area for storage of equipment and for handling of mice - this is also accessible to the animals. Not shown are the feeding and drinking sites ( 3 and 5, respectively, per quarter), the position of the Intelliscales ( 2 per quarter), and further structuring of the floor with bricks and smaller wooden and plastic barriers or hides (modified from [17])

As mentioned before, mice could only access the artificial nest boxes (cylindrical, diameter $15 \mathrm{~cm}$, height $15 \mathrm{~cm}$, covered by a tile) through the tunnel $(44 \mathrm{~mm}$ inner diameter, $6 \mathrm{~mm}$ thickness, $250 \mathrm{~mm}$ length) that was equipped with two round antennas (distance between the two antennas is $15-20 \mathrm{~cm}$; Fig. 3). The tunnels were slightly bent (by an angle of $45^{\circ}$ ) between the two antennas to allow easier adjustment and to slow down the mice when running into a tunnel.

The antennas registered only mice passing through the tunnel and not tagged mice sitting outside, directly next to or on top of the antennas (Helmholtz-designed antennas).

Each antenna was coupled with the animal identification system AniLoc (square black box visible in Fig. 3), and had a unique identification number. The AniLoc device continuously generated a close-range electromagnetic field within its double coil antenna $(666 \mu \mathrm{H}$ inductivity, $50 \mathrm{~mm}$ diameter; the two Helmholtz coils had a distance of $30 \mathrm{~mm}$ ). The $125 \mathrm{kHz}$ low-frequency radio signal emitted by the device activated transponders located in the range of an antenna. The activated transponder then sent its unique code back to the AniLoc reader. Once the complete sequence of the transponder was received, the AniLoc system transmitted the decoded RFID number together with the antenna identification and a timestamp (in ms) through the CAN-bus that interconnected all antennas and the power supply of $12 \mathrm{~V}$. We used rodent proof cables (ALMI PREXTHAN-VA 4G1, $5 \mathrm{~mm}^{2}$ with reinforced steel coating, AlMi $\mathrm{GmbH} \&$ Co. KG, Mülheim, Germany), since mice otherwise may gnaw at and damage unprotected cables.

Optical indication of proper operation is provided with each AniLoc (LED indicators at the bottom of the AniLoc box signaling green versus red light, see lower left picture in Fig. 3).

The AniLoc devices were equipped with two types of auto-calibration. The first was carried out during powerup and measured for each antenna inductive static objects in its surrounding area, like metal or other antennas, which influenced the electromagnetic field. The device automatically adjusted the power of the electromagnetic field and the sensitivity of the antenna (signal amplification and filters) to an optimum. Such calibration minimized the problem of interference with nearby metal- or water-based objects. The second automatic procedure interrupted the operation of an antenna every $20 \mathrm{~s}$ for $50 \mathrm{~ms}$, and checked for its correct impedance to 


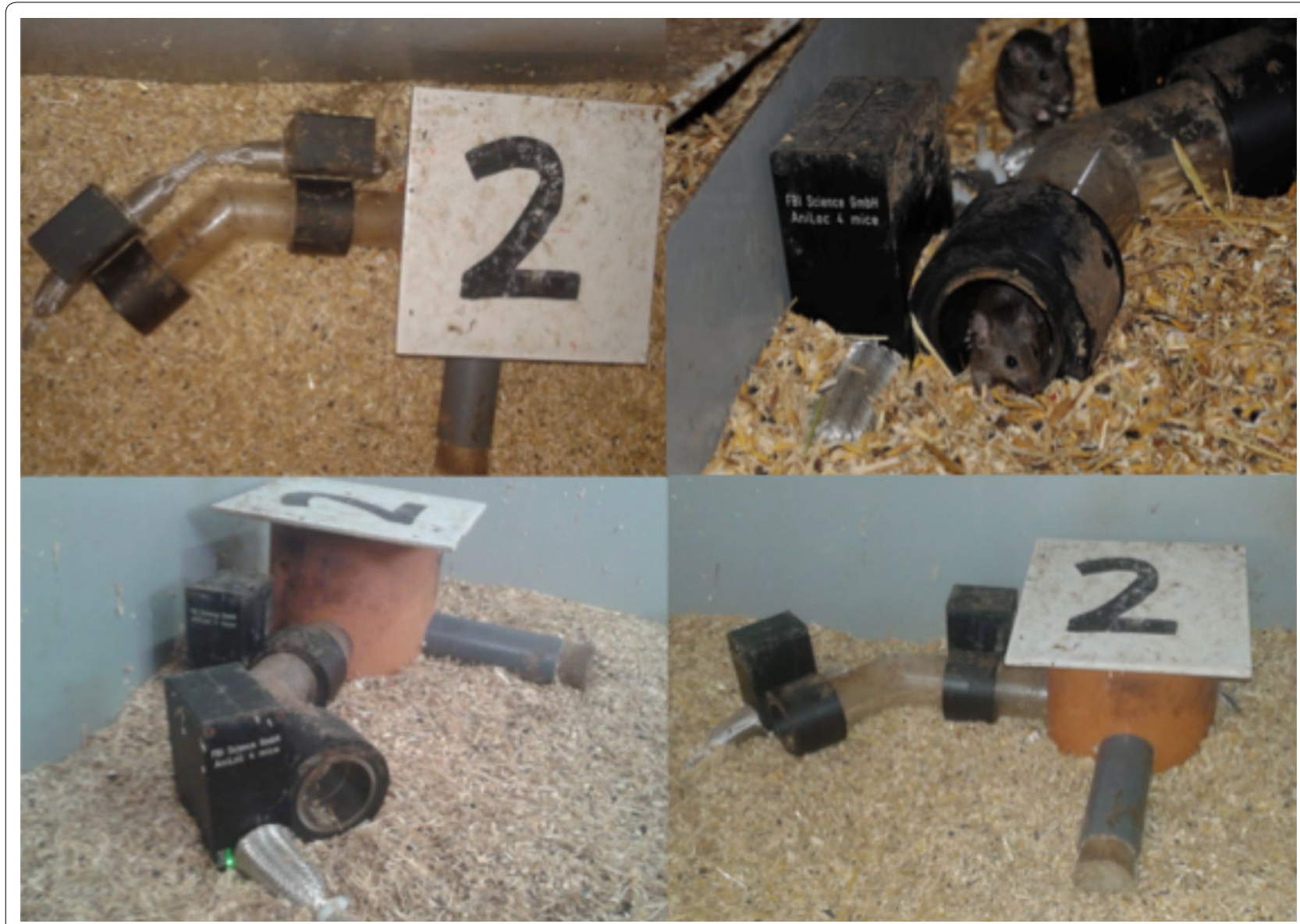

Fig. 3 Mice access nest boxes through acrylic tunnels. Each tunnel is equipped with 2 antennas to allow discrimination between an individual entering or leaving a box. Shown here is (with nest box number 2 as an example) the positioning of the 2 antennas, each connected to an AniLoc device, with a mouse passing through the "outer" antenna (upper right), and a green light signal indicating proper functioning of the device (lower left)

detect short circuits or interruptions. Additionally, that procedure provided a short resting time for the operation of the electromagnetic field, since otherwise the transmitter was in continuous operation (unlike a transponder handheld reader or other RFID products).

The CAN-bus loop terminated on both ends with an interface (CAN2USB-interface "IXXAT", IXXAT Automation $\mathrm{GmbH}$, Germany) to a laptop computer (located in the entrance area of the barn, and protected against mice) running the software OLCUS (FBI Science GmbH, Germany) within the Microsoft operating system "Windows XP". OLCUS analyzed the data stream online in conjunction with the topology of the nest boxes and their antennas. Besides recording the data, OLCUS supervised the proper operation and carried out basic statistical analysis. All data were continuously registered in a log file stored in the onsite laptop. Every $24 \mathrm{~h}$, a copy of the file was automatically sent to a server at the University of Zurich and uploaded into a database.
Furthermore, 8 weighing scales (Intelliscale, FBI Science $\mathrm{GmbH}$, Germany) with a small freely movable platform $(5 \mathrm{~cm}$ diameter) were mounted below water bottles equipped with an antenna below each drinking nipple (Fig. 4). In combination with a PIR (infrared motion sensor), a mouse was detected when moving onto the platform and was identified by its RFID transponder. The weight was registered while drinking water. As soon as the mouse left the platform, the scale was automatically tared (set to zero) to adjust for the weight of any debris or water drops left on top of the platform before the next measurement. The Intelliscales were connected to the same CAN-bus and were fully configurable. For financial and maintenance reasons, we had not equipped all feeding and drinking sites with Intelliscales, and thus collected body weight data rather opportunistically so far.

The four sections of the barn (Fig. 2; with 10 nest boxes and 2 Intelliscales each) could be supplied with power 


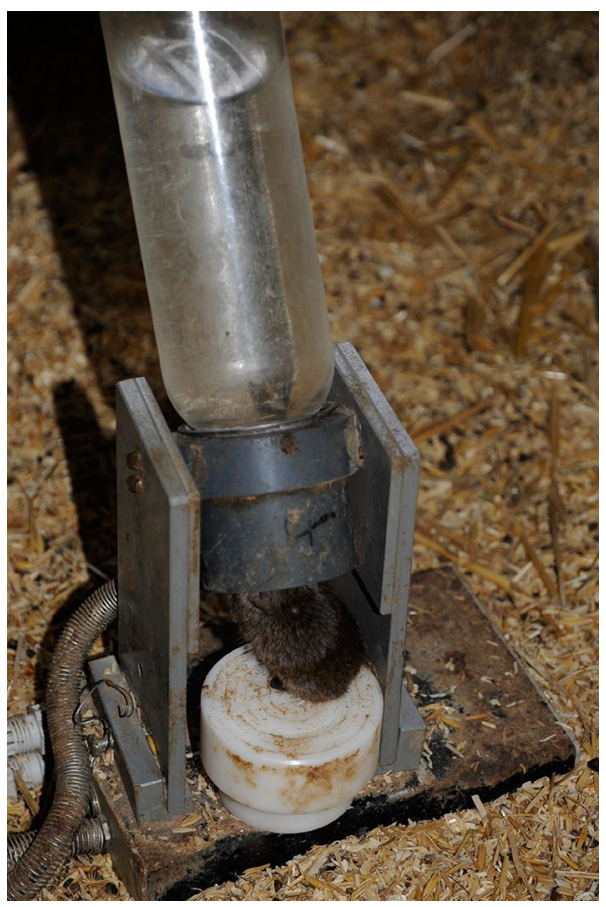

Fig. 4 Intelliscale device (FBI Science GmbH, Germany). A mouse drinks from a water bottle, with its head inside the field of an antenna. It sits on a white, freely movable platform that is connected to a scale in the lower black box. A PIR (infrared motion sensor) is located in the middle of the platform, here partly covered by the mouse

independently of each other, which had been designed for improved failover and maintenance purposes.

\section{Time resolution of RFID transponder readings}

RFID transponder detection speed was $30 \mathrm{~ms}$, so that AniLoc registered a transponder if a tagged mouse ran through the field of the antenna with a speed up to $1 \mathrm{~m} / \mathrm{s}(3.6 \mathrm{~km} / \mathrm{h})$. Bending of the tunnels, as mentioned before, was intended to slow down the mice when running in or out of the tunnels (to avoid missing a reading of an RFID transponder). AniLoc signaled the first event as soon as the transponder entered the electromagnetic field, which triggered an entry message with RFID code and timestamp, as described before (for an example see Table 1). If the registered mouse left the electromagnetic field again within $200 \mathrm{~ms}$, or another tagged mouse entered the same antenna while the previous was still in it, an exit message was given. If a mouse spent a longer time inside the field of an antenna, this resulted in a sequence of messages with the same RFID code.

The technology used could not simultaneously read several transponders (collision detection). In case a second mouse entered the field of an antenna already occupied by a tagged conspecific, RFID codes of the two mice were read randomly. The rather small inner diameter of a tunnel was expected to minimize the probability that two mice entered the field of an antenna in parallel. Nevertheless, we occasionally observed that one mouse squeezed itself on top of another mouse already sitting in a tube.

\section{Ethical note}

Injection and use of PIT tags as well as any other manipulations require a permit according to the Swiss Animal Welfare Ordinance (TSchV). When applying with the authorities for a license to perform animal experiments, methods, practices and reasons for the animal experiment have to be described in detail and are evaluated. Data collection of the project described here was approved by the Veterinary Office Zurich, Switzerland (Kantonales Veterinäramt Zürich, no 151/2010, 56/2013).

\section{Results}

Initial failure of the system to register RFID transponders was due to occasional loosening of the connection between the cable and an AniLoc box. During nest checks and population monitoring, we sometimes had to shift or lift a nest box, with the consequence of loosening the contact of the cable to the box. Mice sometimes also began chewing at those parts of the cable that were not entirely protected by steel coating resulting in connection failures. Covering those parts with additional metal shields (visible in Fig. 3) drastically reduced these problems. Nevertheless, once a week we visually checked the proper operation of the system and inspected the connections between cables and AniLoc boxes.

After a few months of experience with AniLoc, we included additional automatic tests in OLCUS, which were run on both the hardware and software to increase reliability and monitoring of the system.

1. Failures (as antenna short circuits or interruptions, CAN-bus errors) were immediately reported via email to the main users at the University of Zurich.

2. Power loss or connection issues were reported to the main software (in addition to optical indication of proper operation, visualized by a red light at the AniLoc box).

3. Antennas were automatically supervised for proper operation. If no RFID transponder was registered by an antenna within $12 \mathrm{~h}$, an alert message was reported. Given the high density of our study population, all nest boxes were regularly visited. For several years we did not observe that a nest box was left uninhabited for a longer period of time. 
Table 1 Example of raw data output

\begin{tabular}{llccc}
\hline Can timestamp & Date timestamp & Device ID & Antenna ID & Data (RFID code) \\
\hline 3379450851 & $26.01 .201520: 13: 30: 863$ & 8 & 2 & $00-07-5 a-7 c-79$ \\
3379752565 & $26.01 .201520: 13: 31: 063$ & 8 & 2 & $00-07-5 a-7 c-79$ \\
3380086270 & $26.01 .201520: 13: 31: 285$ & 8 & 1 & $00-07-5 d-48-64$ \\
3380783772 & $26.01 .201520: 13: 31: 750$ & 24 & 1 & 1 \\
3381115701 & $26.01 .201520: 13: 31: 971$ & 8 & 1 & $00-07-5 d-48-64$ \\
3381298991 & $26.01 .201520: 13: 32: 094$ & 24 & 2 & 2 \\
3381742523 & $26.01 .201520: 13: 32: 389$ & 24 & 24 & \\
3384199836 & $26.01 .201520: 13: 34: 027$ & 24 & 2 & \\
\hline
\end{tabular}

The mouse with the RFID transponder 00075A7C79 left nest box 8 (Device ID 8). The RFID was first registered at the "inner" antenna (Antenna ID 2) of nest box 8, and shortly afterwards at the "outer" antenna (Antenna ID 1) of the same nest box. Additionally, the system registered that the mouse with RFID $00075 D 4864$ entered nest box 24 . Empty "messages" represent the time when the given individual left the field of the antenna

\section{Recording of data sets in log files}

The AniLoc system was designed to focus on the use of nest boxes by tagged mice to study social interactions. For a population of about 300 individuals (the number of tagged adult mice varied between 214 and 311 during the reproductive seasons in spring and summer 2012 until 2014), the system with 88 antennas (80 attached to the tunnels of the 40 nest boxes, and 8 to the weighing scales) generated daily files containing up to 300,000 lines of data entry. Each line of the log file contained the RFID code of a mouse being read, two timestamps in milliseconds (RFID code sent by the device and RFID code received in OLCUS), the nest box and the antenna number. When the mouse had left the field of an antenna, an empty field was displayed under the RFID code, again with timestamp, nest box and antenna number (Table 1).

\section{Movements into and out of nest boxes}

Each entrance tube of the nest boxes was equipped with two antennas. We used that topology to tell the difference between mice entering and leaving a box. A mouse had entered a box when its transponder was registered at the "outer" antenna of the box (placed near the entrance opening of the tube) and afterwards at the "inner" antenna (placed close to the nest box; see Fig. 3) without having been read at any other antenna in between. The reverse sequence was used to register events of leaving a nest box.

Over a period of 2 months (October and November 2013), we analyzed time intervals between the two antennas of a nest box when tagged mice moved through the tunnels. Number of tagged mice ranged between 206 and 265 during this time period. Mice typically moved rather quickly through the tunnels. Median time interval between the two antennas was $585 \mathrm{~ms}$ when entering ( $n=198,816$ events), and $601 \mathrm{~ms}$ when leaving a nest box $(n=196,460$ events; Fig. 5).
We observed some outliers of several hours, with one value of 11 days, resulting in rather high mean values (mean time intervals \pm SD when entering a nest box: $58.0 \pm 2825 \mathrm{~s}$, when leaving: $30.9 \pm 1358 \mathrm{~s}$ ). However, the majority of values were in the range of up to $25 \mathrm{~s}$, plotted in Fig. 5 (entering: $95.8 \%$ of the time intervals, leaving: $96.6 \%$ ). Unrealistically high values are attributed to various causes. First, they were artifacts of our population maintenance practices. During nest checks (done weekly) or comprehensive trapping of mice (done twice during the 2-month time period), we occasionally detached tubes when mice sat inside, or released individuals back into nest boxes using the otherwise plugged tubes. Mice were sometimes also found dead in nest boxes or in tubes, and when taking them out by hand, we may have moved them in the field of an antenna. Second, an antenna was temporarily not functioning because of connection failure of the cable. Third, the technical constraints of AniLoc to deal with collision detection (as described under Methods) had not registered an RFID in the field of an antenna. Fourth, an antenna failed to register all events of a tagged mouse moving through its field (inefficiency to trigger all events).

\section{Trigger efficiency of antennas}

We estimated the trigger efficiency of the antennas as follows. For the 2-month time period (October to November 2013), we selected all events in which we had registered the sequence of entering and leaving the same nest box $(n=196,423)$. A mouse had entered a nest box when its RFID was registered first at the "outer" and then at the "inner" antenna without registering of this RFID at another antenna, indicating that both antennas of that nest box were functioning on the given day. When the same mouse left the nest box again, we counted the number of incorrect events, in which its RFID code was registered only at one of the two antennas (either the "inner" and not the "outer" antenna, or the "outer" and 

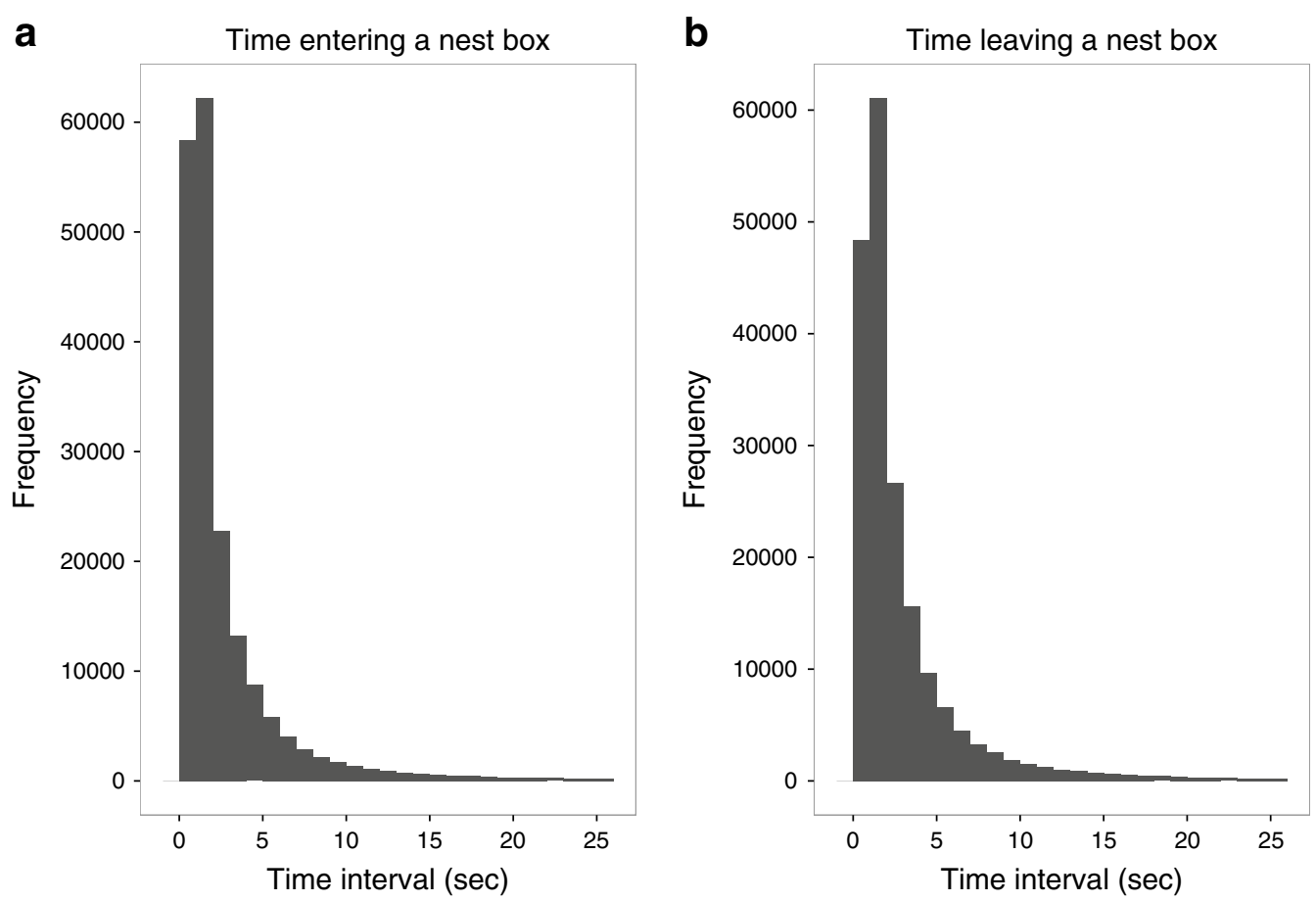

Fig. 5 Histogram of time intervals between the 2 antennas of an entrance tube when tagged mice entered a nest box (a) or left a nest box (b)

not the "inner" antenna) before the mouse showed up in the field of another antenna in the barn. Such failings in registering quantified the antennas' failure rate of reading an RFID when it moved through the field. Trigger efficiency, averaged over a period of 2 months and registering almost 300 tagged mice entering and leaving nest boxes, was $98.9 \%$ (Table 2).

\section{Nest box use and social behavior}

We used the individual events of entering and leaving a nest box to analyze meetings of mice in the nest boxes. We referred to a meeting as those cases when two tagged mice were simultaneously present in the same box. Individuals that regularly and repeatedly met in the same next box were assumed to belong to the same social group. To analyze whether our study population was structured into social groups, we used social network analysis, based on social meetings (encounters within nest boxes) among the mice. Since the house mouse is a crepuscular species, we analyzed nest box use of tagged mice during the night (from sunset until sunrise).

To visualize the social networks and identify separate social groups, we used the program Netdraw [36]. During the night of March 21st to March 22nd 2013, a total of 132 females and 65 males were registered in nest boxes over $12 \mathrm{~h}$. During the 3-day time period of March 20th to $23 \mathrm{rd}$, the population was undisturbed by researchers.
Table 2 Antenna trigger efficiency

\begin{tabular}{lcll}
\hline Month & $\begin{array}{l}\text { Correct events } \\
\text { when entering }\end{array}$ & $\begin{array}{l}\text { Incorrect events } \\
\text { when leaving }\end{array}$ & $\begin{array}{l}\text { Antenna } \\
\text { failure (\%) }\end{array}$ \\
\hline Oct & 100,784 & 996 & 0.99 \\
Nov & 95,639 & 1222 & 1.28 \\
\hline
\end{tabular}

Failure rate in registering RFID transponders by AniLoc during October 1st until November 30th 2013, when population size ranged between 206 and 265 tagged mice. Efficiency was estimated for 80 antennas by counting the number of incorrect registration events when a tagged mouse left a nest box (the individual was not read at either the "inner" or the "outer" antenna) after it had correctly entered the nest box (the individual was first read at the "outer" and afterwards at the "inner" antenna of the same nest box)

Both male and female mice used different nest boxes and met with conspecifics in the same nest box. Females used on average more nest boxes than males (mean $\pm \mathrm{SE}$, females: $2.5 \pm 0.08$; males: $1.2 \pm 0.06$ ). The population was socially structured in at least 11 groups, consisting of members of both sexes (Fig. 6).

To illustrate further applications of the data collected from the antenna system, we analyzed nest box use on the following day (March 22nd 2013). We then combined this dataset with a microsatellite genotype dataset to test if individuals using neighboring boxes were more closely related than individuals using distant boxes. First, we chose a 2-h time period when we expected mice to be relatively inactive (11:00-13:00 h), assuming that they rested 


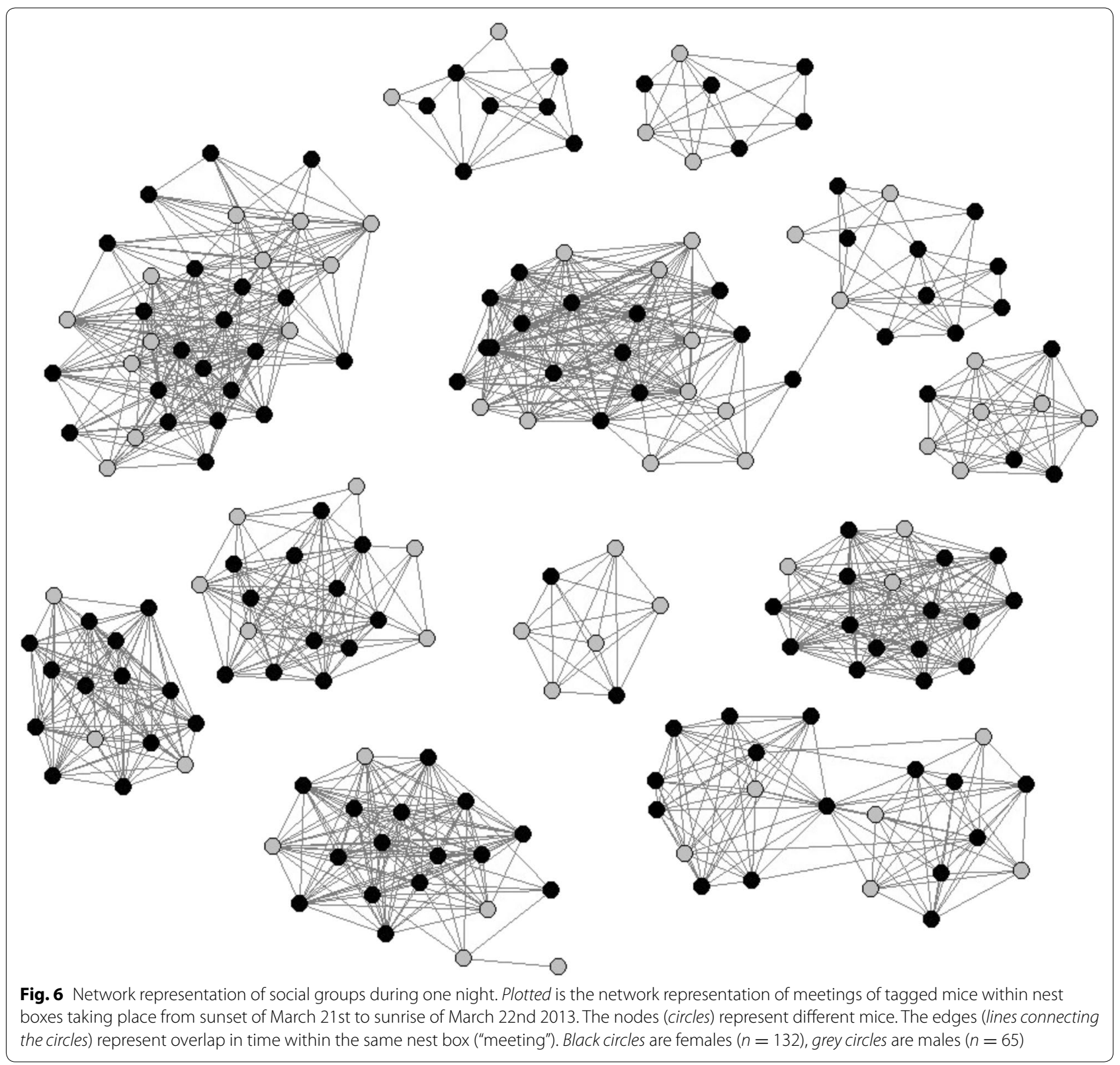

with their most preferred social partner(s). During these $2 \mathrm{~h}, 33$ females and 43 males were recorded by the antenna system. Again, females entered a larger number of different nest boxes than males (mean \pm SE, females: $1.8 \pm 0.19$, range 1-5; males $1.2 \pm 0.07$, range $1-3$; Wilcoxon rank sum test $W=931, p<0.01$ ). Time spent within nest boxes varied greatly among individuals, ranging from $1 \mathrm{~s}$ to 119 min. A mouse had left the nest box (after it had correctly entered it; see before) when its transponder was read at the "outer" antenna before it was registered at any other antenna in the barn. When mice moved in the nest box, they were repeatedly read at the "inner" antenna. We nevertheless considered an individual inside a nest box until it had finally left (last registration at the "outer" antenna before it was registered at any other antenna of another nest box). Overall, females and males did not differ significantly in total amount of time spent within nest boxes (Fig. 7; Wilcoxon rank sum test, $W=606.5, p=0.28$ ).

We performed a spatial genetic analysis using GenAlEx 6.5 [37] to compare genetic similarity between mice depending on their physical location. To do this, we first assigned each mouse to one nest box. In cases where multiple boxes were used, we accorded location to the nest box in which the duration of stay was the longest. Using nest box locations in $X$ and $Y$ coordinates, we used GenAlEx to calculate a geographic distance matrix 

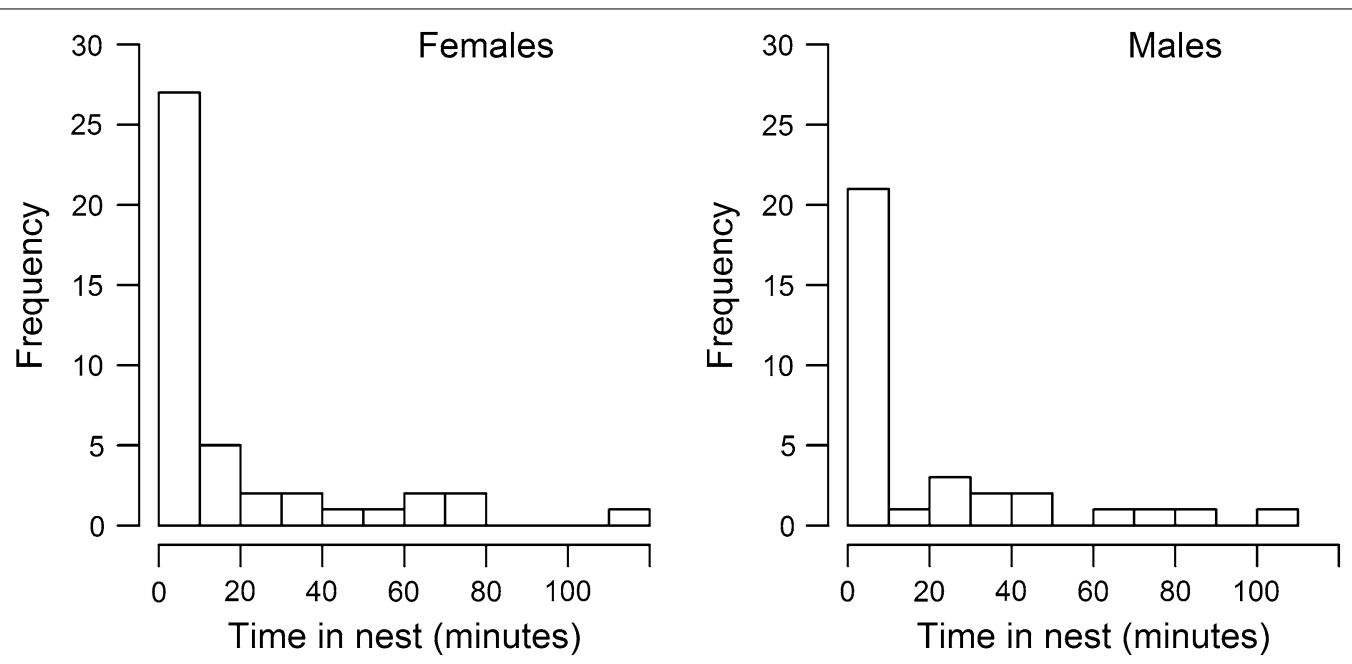

Fig. 7 Histogram of total time spent within nest boxes by tagged mice during a 120-min period (11:00-13:00 h, on March 22nd 2013), by sex

between all individuals recorded. Using 25 microsatellite genotypes generated for parentage analysis (see [33] for details), we similarly calculated a genetic distance matrix for the same set of individuals. One mouse was excluded because of missing genotype information. The spatial genetic analysis computed a genetic autocorrelation between a focal individual genotype and genotypes of every other mouse within a distance class of $1 \mathrm{~m}$ and for others farther away, as though concentric rings are drawn around the focal individual, each one increasing in radius by one distance class, and with each ring capturing the location of different individuals. This was then repeated over all tagged mice, and permuted randomly for significance testing.

For both females and males, we found significant genetic correlations between individuals located up to $1 \mathrm{~m}$ apart $(p<0.001)$, and $2 \mathrm{~m}$ apart $(p<0.001)$. For males, individuals $3 \mathrm{~m}$ apart were also significantly more correlated $(p<0.045)$ than male conspecifics further away. At greater distances, however, the correlations decayed to zero and below (Fig. 8). These results suggest that mice from this population of both sexes tended to be found near genetically similar individuals, that is, near relatives.

\section{Discussion}

The AniLoc system was designed to focus on nest box use. In their natural environment, house mice are dependent on safe places or nests to retreat from predators, to provide a suitable microclimate, and to allow for survival and successful reproduction (for reviews, see $[17,30])$. During cold periods, huddling in nests is expected to provide thermoregulatory benefits. In social species, the frequency and duration of meetings between

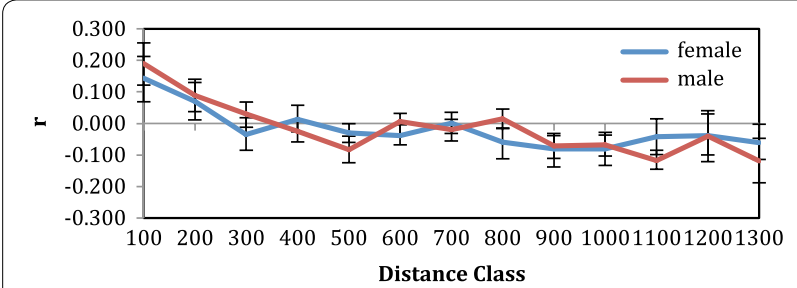

Fig. 8 Plot of genetic autocorrelation by distance and by sex. Estimates and $95 \%$ confidence intervals obtained by bootstrapping are shown

individuals are assumed to reflect the type of interaction [38]. Cooperation during communal nursing, for example, requires a shared home range with access to a suitable nest. In addition, litters are vulnerable not only to the same predators as adults, but also to conspecifics that kill unrelated pups if given the opportunity [30, 33, 39]. Breeding females may, therefore, prefer places that can be defended against such infanticide. We rarely found that females used locations outside of nest boxes for breeding. Given the importance of safe nests, as provided with our artificial nest boxes, we are confident to use nest box usage as a proxy for an individual's "home range" and its membership to a social group. The frequency, duration and patterns of associations with conspecifics (and litters) will further be used as a correlate for the strength of social preferences and social bonds.

\section{Social behavior revealed by the use of nest boxes}

The AniLoc system provided data on meetings between mice in nest boxes for social networks at a high resolution. Social networks have proved to reveal valuable information on the mechanisms and functions of group living in animal species [40-43], on the spread of diseases 
or behavioral innovations [44-47], as well as on dispersal [48]. For our study population, social network visualization revealed structuring in eleven or twelve social groups (Fig. 6; two networks were linked by one female only), consisting of both males and females, during a single night.

AniLoc did not allow documenting interactions outside of nest boxes, but it is interesting to note that groups were rather socially closed when analyzing meetings in nest boxes. Mice visited more than one nest box during a single night. However, they did not visit nest boxes over large areas in the barn, but were rather restrictive in the use of usually neighboring nest boxes, suggesting that this reflects their "home range" that is regularly used and patrolled. Future analyses will focus on the persistence and duration of social stability in groups, and the impact of group member death or immigration of a previously unfamiliar individual.

It is not known whether group members jointly defended nest boxes against non-group members. Social closeness, nevertheless, suggests individualized relationships among group members and their importance for social behavior. Both sexes had several partners (of both sexes) and females used significantly more nest boxes than males. This contradicts previous studies that characterized the social system of house mice of one dominant male monopolizing access to several females [49-51], and illustrates social flexibility among both sexes. Access to nest boxes exclusively used by group members may be a crucial resource for females to breed successfully (see also [17]). It is difficult to individually mark the study population for behavioral observations but, nevertheless, direct or video observations may reveal preliminary evidence whether mice defend entrance tunnels against members of other social groups.

Even more interesting was our observation of spatial genetic structuring of the population. Both female and male mice shared nest boxes with relatives, which is an indication of either kin recognition or viscosity in terms of genetic mixing among individuals in the study population [52, 53]. Given such spatial genetic viscosity, individuals might gain indirect fitness benefits if cooperative behavior (even in the absence of kin recognition) is directed only at conspecifics in close range. Combined, the observations that mice lived in rather closed social groups and tended to share nest boxes with relatives highlight the importance of kin selection for the evolution and maintenance of social behavior such as communal nursing among females.

Mice have to leave nest boxes for feeding, territorial defense, searching for mates and other activities. In addition to information on social interactions, we also automatically documented data on individual activity budgets, which can be analyzed by plotting the daily distribution of antenna recordings and time spent in nest boxes for mice differing in sex and in reproductive status (breeding or non-breeding), and for different seasons.

\section{Constraints and validity of the technology used}

RFID transponder detection speed was $30 \mathrm{~ms}$, so that AniLoc registered a transponder if a tagged mouse ran through the antenna with a speed up to $1 \mathrm{~m} / \mathrm{s}(3.6 \mathrm{~km} / \mathrm{h})$. Given a minimal distance of $15 \mathrm{~cm}$ between the "outer" and the "inner" antenna, and a median time interval of 600 ms needed by the mice to cover that distance, they entered and left the nest boxes with a speed of $0.03 \mathrm{~m} / \mathrm{s}$, which is within the antennas' detection capacity. The design of our entrance tunnels (relatively small diameter, bent in the middle) in combination with the antennas' technical characteristics, therefore, allows for rather reliable registration of RFID tags.

The inner diameter of a tunnel minimized the probability that two mice entered the field of an antenna in parallel. Still, we sometimes observed that one mouse squeezed itself on top of another mouse already sitting in a tube. In such a case, AniLoc randomly registered one of the two RFID codes (collision detection). We nevertheless argue that missed recordings because of collision detection were rather infrequent. "Correct" registrations when entering and leaving a nest box $(n=194,205$ events, Table 2) were high in comparison to the number of registrations of any event of movements in tunnels (entering: $n=198,816$, leaving: $n=196,460$, Fig. 3). This suggests that maximally $2 \%$ of events had been affected by missing registration due to the technical constraint of collision detection. Since other technical or maintenance problems, as described before, also resulted in missing readings, the value may even be lower. A high trigger efficiency of $98.9 \%$ of the antennas, and the fact that each tunnel was equipped with two antennas, further supports our conclusion that mice were registered when moving into or out of nest boxes with very high reliability.

The AniLoc system does not constrain users to the RFID transponders described here $\left(\operatorname{trovan}^{\circledR}\right)$, but allows for flexibility. It also reads $134 \mathrm{kHz}$ ISO-FDX-B "white label" transponders provided by PlanetID ( $0.03 \mathrm{~g}$ weight, $9.0 \mathrm{~mm}$ length, $1.4 \mathrm{~mm}$ diameter).

The size of a transponder affects the minimum body size for implantation. In our study population, we stopped implanting mice of below $18 \mathrm{~g}$, as initially done, since such subadults relatively often lost the transponder again (typically within a few days after tagging). Using smaller transponders might improve retention in smaller mice, but at the disadvantage of shorter reading distance (decreasing trigger efficiency). We also considered a cost advantage of tagging mice only when they reached $18 \mathrm{~g}$ 
as the majority of subadults disappeared (emigrated) out of the barn before sexual maturity. Furthermore, mean age of reproduction of females was 263 days (9 months) in our population [31]. We, therefore, did not risk missing information on the reproductive behavior of adult females and males. We did, nevertheless, fail to document the development of social relationships during early life, after weaning and before reaching the size of a potentially sexually mature individual.

Non-invasive monitoring of tagged animals does not necessarily require an automatic system as described here. It is also possible to study social cooperation and group structure with handheld transponder readers that allow reading of RFID numbers from outside a nest box or another shelter as a tree hole (such a method was used by [24] for house mice, and by [13, 14] for Bechstein's bats). This method, however, does not always result in reliable information on all individuals present in a nest box or shelter, especially if many individuals rest or sleep close together and not all RFIDs will be registered [13]. In our study population, we also regularly missed recording some RFIDs with handheld devices since mice sometimes fled out of shelters when a researcher closely approached the nest box with the device. Most importantly, handheld devices do not allow recording of how much time an individual spent in a nest box and how much of that time was shared with other adults.

Other studies with laboratory mice also automatically collected behavioral data with custom-designed small animal tracking systems. RFID technology and PIT tags were used to track individuals in large enriched environments to study aspects of their neurobiology or brain development [54]. Freund and co-workers monitored the locations and the drinking behavior of 40 tagged laboratory mice in a large enriched enclosure over 2 months. Twenty RFID antennas were positioned around tunnels connecting different levels in the enclosure, and around shorter tunnels leading into nesting boxes and to water sources. This system, however, did not allow for detailed analyses of social interactions.

The antenna system described here is not restricted to studying house mice in their natural environment but can be used for other secretive and generally difficult to observe small mammals, such as other rodents, insectivores, bats, or also birds. It requires that the animals can be tagged with RFID transponders and that they use or congregate at sites as shelters, breeding or feeding sites whose access can be fitted with antennas. When installed in captivity or in the laboratory, the system also registers automatically and non-invasively individualized longterm data of group living animals, and thus is helpful for empirical research as for example on circadian activity, learning, cognition, social experience, or animal welfare.

\section{Outlook}

The AniLoc RFID transponder reading system allowed continuous recording of nest box usage of all adult (tagged) members of a free-living population of wild house mice (Mus musculus domesticus). We will use it to track individuals over their adult lifespan, until they die or emigrate from the barn. The data can also be used to analyze home ranges, dispersal within the study population, group composition and social interactions among mice over the entire lifetime of an individual-or until it emigrates out of the study population.

The Intelliscale device collected data on individual body weight when drinking. It required, however, regular maintenance to clean the device from bedding or feces that accumulated under or on the platform. We are currently analyzing the accuracy of the device's automatic taring (set to zero in between measurements) and thus of the body weight measurements. Nevertheless, we are confident that the device will allow information on the day and time of birth of litters or of failed pregnancies (drastic drop in body weight of females that had been registered as pregnant before). The timing and duration of drinking behavior may further reveal information on social dominance, assuming that subordinates cannot feed and drink during the preferred or safest time of day, but only when the dominant(s) are not active. Since mice typically drink shortly after a feeding bout, access to the water bottle is expected to correlate with access to an important resource. The Intelliscales also register the body weight of untagged mice. Although such data do not allow individual information, they may nevertheless reveal differences in the behavior of subadult and adult mice.

We combine in a single database the behavioral and spatial information from the antenna system with morphometric data (mostly collected by hand during population and litter monitoring, partly collected automatically with the Intelliscales) and genetic data (tissue samples taken from pups, adults at the time of tagging and deceased untagged individuals). We thus gain additional information on individual longevity, life histories and reproductive success, information that is otherwise difficult or even impossible to be collected on a population wide scale in a species' natural environment. We can further gain information whether the described spatial genetic structuring of the population is stable over longer time periods, or whether it is modified by season or population density.

The antenna data already allowed first analyses of basic questions in behavioral ecology such as the evolution of cooperation (ultimate and proximate causes of social behavior and cooperation during communal nursing; [24, $33]$ ) or sexual selection [31, 32]. It will further contribute 
to other fields of research, such as population ecology, population genetics and disease ecology, and may be a very useful tool in wildlife and conservation biology.

\section{Authors' contributions}

BK initiated the project, conceived and designed the study, contributed to data acquisition and wrote the manuscript. AL contributed to the study design, data acquisition, data analyses and to writing the manuscript. PL contributed to data acquisition, data analyses and to writing the manuscript. $\mathrm{AD}$ contributed to data acquisition and data analyses. SS contributed to the study design and to data acquisition. FB designed and set-up the technology (AniLoc and Intelliscale), contributed to data analyses and writing the manuscript. All authors read and approved the final manuscript.

\section{Authors' information}

BK is a zoologist and head of the Animal Behavior Group at the Institute of Evolutionary Biology and Environmental Studies at the University of Zurich, Switzerland (EBES UZH). She studies social evolution in small mammals, both in the field and in the laboratory. AL is a Group Leader at EBES UZH. She is interested in fitness differences between wild mice, and the extent to which these are influenced by social behavior, and traceable to the effects of genes. $\mathrm{PL}$ is a postdoctoral researcher at EBES UZH. She is interested in understanding the mechanisms underlying social behavior, particularly in the context of disease. AD is a theoretical physicist and a postdoctoral researcher at EBES UZH. He uses bioinformatics to model and analyze biological systems, with a focus on social behavior. SS is a field zoologist and ecologist, specializing on small group-living mammals. She studied at the University of Queensland but now works at EBES UZH and supervises the maintenance of the study population, the transponder reading devices and data collection. FB is a biopsychologist and CEO of FBI Science GmbH, a company that develops and sells equipment and software for animal health surveillance, animal behavior measurement and automated gateways.

\section{Author details}

1 Institute of Evolutionary Biology and Environmental Studies, University of Zurich, Winterthurerstrasse 190, 8057 Zurich, Switzerland. ${ }^{2}$ FBI Science GmbH, Kempstrasse 77, 41748 Viersen, Germany.

\section{Acknowledgements}

We are extremely thankful to our numerous helpers (students, Institute and group members) who contributed to catching, measuring and tagging mice over the last 12 years. We would like to especially mention Gabriele Stichel, our animal caretaker, for tagging many hundreds of mice. The editor as well as Wlodek Mandecki and James Littelmoer provided comments that substantially improved the manuscript. This study was financially supported by the University of Zurich, the Swiss National Science Foundation, Claraz foundation, Promotor Stiftung, Stiftung für wissenschaftliche Forschung UZH, Baugarten Sitftung, Wolfermann-Nägeli-Stiftung. All their help and support is sincerely acknowledged.

\section{Compliance with ethical guidelines}

\section{Competing interests}

FB is owner of FBI Science GmbH, Germany that developed the AniLoc and Intelliscale devices and sold them to the research group in Zurich. Hence, bias in terms of objective evaluation of the system cannot be excluded. The other authors (BK, AL, PL, AD and SS) declare that they have no competing interests.

Received: 27 January 2015 Accepted: 7 September 2015

Published online: 05 October 2015

\section{References}

1. Krause J, et al. Reality mining of animal social systems. Trends Ecol Evol. 2013;28(9):541-51.

2. Gibbons JW, Andrews KM. PIT tagging: simple technology at its best. Bioscience. 2004;54(5):447-54.
3. Orpwood JE, et al. Efficacy of artificial shelters for roach, Rutilus rutilus, against predators in the presence of reeds. Fish Manag Ecol. 2010;17:356-65

4. Rehage JS, et al. Turning passive detection systems into field experiments: an application using wetland fishes and enclosures to track finescale movement and habitat choice. Acta Ethologica. 2014;17:53-61.

5. Charney ND, et al. Terrestrial passive integrated transponder antennae for tracking small animal movements. Wildlife Manag. 2009;73(7):1245-50.

6. Dittmann T, Becker PH. Sex, age. experience and condition as factors affecting arrival date in prospecting common terns, Sterna hirundo. Anim Behav. 2003;65:981-6.

7. MacLeod R, Gosler AG, Cresswell W. Diurnal mass gain strategies and perceived predation risk in the great ti Parus major. J Anim Ecol. 2005;74(5):956-64.

8. Wilkin TA, King LE, Sheldon BC. Habitat quality, nestling diet, and provisioning behaviour in great tits Parus major. J Avian Biol. 2009;40:135-45.

9. Nomano FY, et al. Validation of an automated data collection method for quantifying social networks in collective behaviours. Behav Ecol Sociobiol. 2014;68:1379-91.

10. Afanasyev $V$, et al. Increasing accuracy: a new design and algorithm for automated measuring weights, travel direction and radio frequency identification (RFID) of penguins. PLoS One. 2014;10(4):e0126292.

11. Bonter DN, Bridge ES. Applications of radio frequency identification (RFID) in ornithological research: a review. J Field Ornithol. 2011;82(1):1-10.

12. Harper SJ, Batzli GO. Monitoring use of runways by voles with passive integrated transponders. J Mammal. 1996;77(2):364-9.

13. Kerth G, König B. Transponder and an infrared-videocamera as methods used in a field study on the social behaviour of Bechstein's bats (Myotis bechsteini). Myotis. 1996;34:27-34.

14. Kerth G, König B. Fission, fusion and nonrandom associations in female Bechstein's bats (Myotis bechsteinii). Behaviour. 1999;136:1187-202.

15. Rehmeier RL, Kaufman GA, Kaufman DW. An automatic activity-monitoring system for small mammals under natural conditions. J Mammal. 2006;87(3):628-34.

16. Britzke ER, Gumbert MW, Hohmann MG. Behavioral response of bats to passive integrated transponder tag reader arrays placed at cave entrances. J Fish Wildlife Manag. 2014;5(1):146-50.

17. König B, Lindholm AL. The complex social environment of female house mice (Mus domesticus). In: Macholan M, et al., editors. Evolution in our neighbourhood. The house mouse as a model in evolutionary research. Cambridge: Cambridge University Press; 2012. p. 114-34.

18. Southwick $\mathrm{CH}$. Regulatory mechanisms of house mouse populations: social behavior affecting litter survival. Ecology. 1955;36:627-34.

19. Sayler A, Salmon M. An ethological analysis of communal nursing by the house mouse. Behaviour. 1971;40:60-85.

20. König B. Behavioural ecology of kin recognition in house mice. Ethol Ecol Evol. 1989;1:99-110.

21. König B. Maternal investment of communally nursing female house mice (Mus musculus domesticus). Behav Process. 1993;30(1):61-74.

22. Manning $C J$, et al. Communal nesting and communal nursing in house mice, Mus musculus domesticus. Anim Behav. 1995;50(3):741-51.

23. König B. Fitness effects of communal rearing in house mice: the role of relatedness and familiarity. Anim Behav. 1994;48:1449-57.

24. Weidt A, Lindholm AK, König B. Communal nursing in wild house mice is not a by-product of group living: females choose. Naturwissenschaften. 2014;101(1):73-6.

25. König B, Riester J, Markl H. Maternal care in house mice (Mus musculus): II. The energy cost of lactation as a function of litter size. J Zool Lond. 1988;216:195-210.

26. Queller DC.W. D. Hamilton and the evolution of sociality. Behav Ecol. 2001;12(3):261-4.

27. Doebeli M, Hauert C. Limits of Hamilton's rule. J Evol Biol. 2006;19:1386-8.

28. Lehmann L, Keller L. The evolution of cooperation and altruisma general framework and a classification of models. J Evol Biol. 2006;19:1365-76.

29. König B. Non-offspring nursing in mammals: general implications from a case study on house mice, in Cooperation in Primates and Humans. In: Kappeler PM, van Schaik CP, editors. Mechanisms and evolution. Berlin: Springer; 2006. p. 191-205. 
30. Latham N, Mason G. From house mouse to mouse house: the behavioural biology of free-living Mus musculus and its implications in the laboratory. Appl Anim Behav Sci. 2004;86:261-89.

31. Manser $A$, et al. Polyandry and the decrease of a selfish genetic element in a wild house mouse population. Evolution. 2011;65(9):2435-47.

32. Lindholm AK, et al. Mate choice for genetic compatibility in the house mouse. Ecol Evol. 2013;3(5):1231-47.

33. Auclair $Y$, et al. Nest attendance of lactating females in a wild house mouse population: benefits associated with communal nesting. Anim Behav. 2014;92:143-9.

34. Berry RJ. Town mouse, country mouse: adaptation and adaptability in Mus domesticus (M. musculus domesticus). Mamm Rev. 1981;11(3):91-136.

35. Pocock MJO, Searle JB, White PCL. Adaptations of animals to commensal habitats: population dynamics of house mice Mus musculus domesticus on farms. J Anim Ecol. 2004;73:878-88.

36. Borgatti SP. NetDraw software for network visualization. Lexington: Analytic Technologies; 2002.

37. Peakall R, Smouse PE. GenAIEx6.5: genetic analysis in Excel. Population genetic software for teaching and research-an update. Bioinformatics. 2012;28(19):2537-9.

38. Kerth G, Perony N, Schweitzer F. Bats are able to maintain long-term social relationships despite the high fission-fusion dynamics of their groups. Proc Royal Soc B. 2011;278:2761-7.

39. Parmigiani S, Vom Saal FS, editors. Infanticide and parental care. London: Harwood Academic Publishers; 1993.

40. Krause J, Croft DP, James R. Social network theory in the behavioural sciences: potential applications. Behav Ecol Sociobiol. 2007;62:15-27.

41. Wolf JBW, et al. Social structure in a colonial mammal: unravelling hidden structural layers and their foundations by network analysis. Anim Behav. 2007;74:1293-302.
42. Hansen $\mathrm{H}$, et al. Social networks and the formation and maintenance of river otter groups. Ethology. 2009;115:384-96.

43. Nuñez CMV, Adelman JS, Rubenstein DI. Sociality increases juvenile survival after a catastrophic event in the feral horse (Equus caballus). Behav Ecol. 2014. doi:10.1093/beheco/aru163.

44. Salathé $M$, Jones JH. Dynamics and control of diseases in networks with community structure. PLoS Comput Biol. 2010;6(4):e1000736.

45. Maher SP, et al. Spread of white-nose syndrome on a network regulated by geography and climate. Nat Commun. 2012;3:1306.

46. Mann J, et al. Social networks reveal cultural behaviour in tool-using dolphins. Nat Commun. 2012;3:980.

47. Whitehead H, Lusseau D. Animal social networks as substrate for cultural behavioural diversity. J Theor Biol. 2012;294:19-28.

48. Rollins $L A$, et al. Building genetic networks using relatedness information: a novel approach for the estimation of dispersal and characterization of group structure in social animals. Mol Ecol. 2012;21:1727-40.

49. Crowcroft P, Rowe FP. Social organization and territorial behaviour in the wild house mouse (Mus musculus L.). Proc Zool Soc Lond. 1963;140:517-31.

50. Lidicker WZJ. Social behaviour and density regulation in house mice living in large enclosures. J Anim Ecol. 1976;45:677-97.

51. Mackintosh JH. Behaviour of the house mouse. Symp Zool Soc Lond. 1981;47:337-65.

52. Hamilton WD. The evolution of altruistic behavior. Am Nat. 1963;97:354-6.

53. Hamilton WD. The genetical evolution of social behaviour (I and II). J Theor Biol. 1964;7:1-16, 17-52.

54. Freund J, et al. Emergence of individuality in genetically identical mice. Science. 2013;340:756-9.

\section{Submit your next manuscript to BioMed Central and take full advantage of:}

- Convenient online submission

- Thorough peer review

- No space constraints or color figure charges

- Immediate publication on acceptance

- Inclusion in PubMed, CAS, Scopus and Google Scholar

- Research which is freely available for redistribution

Submit your manuscript at

www.biomedcentral.com/submit

C Biomed Central 